\title{
Absence of lymphatic filariasis infection among secondary-school children in Oman
}

\author{
S.T. Al Awaidy, ${ }^{1}$ S. Bawikar, ${ }^{1}$ P.K. Patel, ${ }^{2}$ P. Kurup, ${ }^{3}$ G.S. Sonal, ${ }^{4}$ S. Al Mahrooqi' and R. Ramzy ${ }^{7}$
}

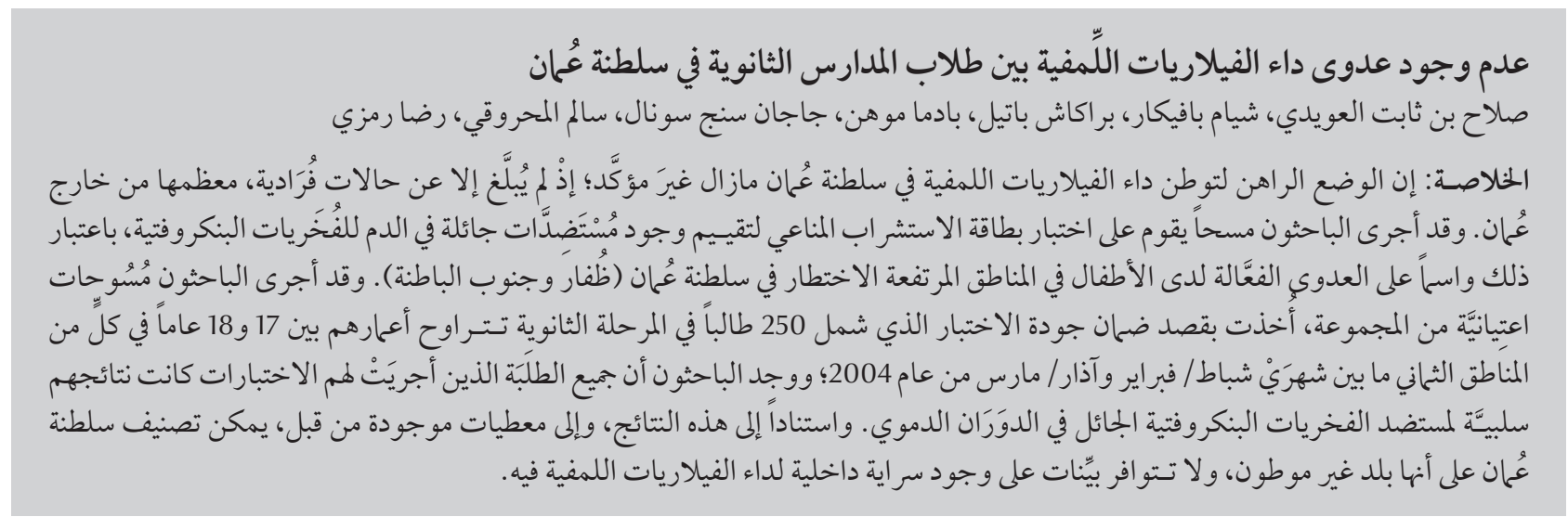

ABSTRACT The endemicity status of lymphatic filariasis in Oman is uncertain, with only sporadic cases reported, mostly imported. Immunochromatographic card test surveys were carried out to assess the presence of circulating Wuchereria bancrofti antigenaemia as a marker for active infection in children from suspected high-risk areas of Oman (South Batinah and Dhofar). Lot quality assurance sampling surveys were carried out on a minimum of 250 secondary-school children aged 17-18 years in each of 8 districts from February 2004 to March 2004. All tested students were negative for circulating $W$. bancrofti antigen. Based on these findings as well as previous data, Oman may possibly be classified as a nonendemic country, with no evidence of indigenous lymphatic filariasis transmission.

\begin{abstract}
Absence de filariose lymphatique chez les élèves de l'enseignement secondaire à Oman
RÉSUMÉ Le statut de l'endémicité de la filariose lymphatique à Oman est flou : seuls des cas sporadiques, pour la plupart importés ont été notifiés. Des études fondées sur des tests immunochromatographiques sur carte ont été effectuées pour déterminer la présence d'antigènes circulants spécifiques de Wuchereria bancrofti, en tant que marqueur d'une infection active chez les enfants dans les régions suspectées de présenter un haut risque à Oman (Batinah-sud et Dhofar). Un sondage pour le contrôle de la qualité des lots a été réalisé sur un minimum de 250 élèves de l'enseignement secondaire âgés de 17 à 18 ans, dans chacun des huit districts entre février et mars 2004. Tous les élèves testés présentaient des résultats négatifs pour l'antigène circulant spécifique de $W$. bancrofti. En fonction de ces résultats et de données précédentes, Oman peut être classé comme un pays non endémique ne présentant aucun signe de transmission indigène de la filariose lymphatique.
\end{abstract}

'Department of Communicable Disease Surveillance and Control, Ministry of Health, Muscat, Oman (Correspondence to S.T. Al Awaidy: salah.awaidy@gmail.com).

${ }^{2}$ Department of Health Affairs, Dhahira Region, Oman

${ }^{3}$ Department of Health Affairs, South Batinah Region, Oman.

${ }^{4}$ Department of Health Affairs, Dhofar Region, Oman.

Received: 07/01/09; accepted: 19/02/09 


\section{Introduction}

Lymphatic filariasis (LF) is one of the most debilitating, disfiguring and stigmatizing diseases of the tropical and subtropical regions of the world. LF is endemic in more than 80 countries. It is estimated that 120 million people are infected and one-third of them suffer from chronic manifestations of the disease. Worldwide, an additional 1 billion individuals are at risk of acquiring the infection [1-4]. The World Health Organization (WHO) estimates that 5.1 million disability-adjusted life years (DALYs) are lost due to LF [5].

Estimates suggest that approximately 12.6 million LF-infected individuals, $1 \%$ of the LF global burden, live in countries of the Eastern Mediterranean Region, where LF is entirely caused by Wuchereria bancrofti and is transmitted primarily by Culex spp. mosquitoes in mostly rural and semi-urban areas [6]. LF is endemic in Egypt, Sudan and Yemen and is targeted for elimination under the Global Programme for the Elimination of Lymphatic Filariasis (GPELF) [7]. The LF situation in Djibouti, Oman, Pakistan, Saudi Arabia and Somalia is currently described as uncertain. However, clinical cases have been reported from Oman, Pakistan, Saudi Arabia and Somalia [4,7].

Oman has a population of approximately 2.34 million, of whom $23.9 \%$ are expatriates (2003 census data). Many of these expatriates are from LFendemic countries such as Egypt, India and Sri Lanka. LF is a notifiable disease in Oman, and between 1991 and 2001 15 cases were reported, mostly classified as imported based on the history of the patient's stay in LF-endemic countries. Of these, 7 were Omanis who lived for some time in LF endemic areas $[6,8]$. With such sporadic cases it is necessary to verify the LF status of Oman. A study conducted by Scrimgeour et al. found an LF antigenaemia prevalence of $4.2 \%$ based on the immunochromatographic test (ICT) among Indian expatriates living in Oman [9]. However, in the global perspective, Oman is included among countries with an uncertain LF situation, i.e. there is no clear evidence either of the presence or absence of local transmission [6].

The ICT filariasis card test is a rapid format test that detects circulating filarial antigens released by adult worms [10] and can thus detect active infection independent of microfilaraemia. Several field studies have evaluated the rapid test and showed that the ICT test can use blood collected during the day or night; the sensitivity of the test reached $98 \%-100 \%$ among microfilaria carriers with $100 \%$ specificity $[11-14]$. Therefore, WHO has recommended the use of the ICT card test for mapping LF endemic areas [15].

The present study aimed to evaluate the LF status in Oman by carrying out ICT-card surveys to detect $W$. bancrofti antigenaemia among secondary-school children aged $17-18$ years in these 2 regions.

\section{Methods}

\section{Study design}

This was a lot quality assurance sampling (LQAS) school-based survey conducted during the academic year 2004-05 among secondary-school children from areas identified as having the potential for LF transmission.

\section{Study area}

The process of verification included initial use of qualitative methods (questionnaire surveys of key informants) to identify possible LF endemic areas. This was followed by LQAS antigenaemia surveys in these possible endemic areas. The key informant surveys identified 2 possible LF endemic areas: South Batinah and Dhofar region (administratively described as the governorate of Dhofar).

Initial rapid assessment questionnaire surveys had revealed that the probability of local transmission was highest in the 6 districts of South Batinah region and 2 districts representing $81 \%$ of the population in the Dhofar governorate. Hence, the current antigen surveys were conducted in these 8 districts of 2 regions of Oman.

\section{Study population}

The target population was children aged $17-18$ years attending secondary schools. The rationale for selecting this age group for the surveys was that LF is a chronic disease with a long incubation period that requires repeated exposure over an extended period of time before the infection is acquired. It takes even longer for the clinical signs and symptoms of lymphatic obstruction to appear. Therefore, the secondaryschool students of this age group would offer epidemiological evidence of the presence or absence of indigenous LF infection in Oman because they would represent an exposure history of 17-18 years.

\section{Sampling}

The WHO guidelines for preparing and implementing a national plan to eliminate LF require that LQAS surveys are conducted to assess the prevalence of antigenaemia in a district to decide on initiation of mass treatment. Thus it was decided that a sample of 250 children from the target age group from each district would be examined using ICT. A cut-off point of $1 \%$ was set to classify the district as endemic for LF [16].

Out of 6 districts from South Batinah region 3 districts have a significantly lower population compared with the other 3 . Hence, it was decided to test the whole secondary-school population in these 3 districts $(295,235$ and 257 students). In the other 3 districts, Barka, Musanah and Rustaq, the selection of the students was done according to the proportional target population. Thus 358, 347 and 506 students were selected from these districts respectively, by considering each class in the secondary 
schools as 1 cluster and randomly selecting the classes. Similarly, 499 and 248 students were selected from Salalah and Taqah districts of Dhofar region respectively.

\section{Survey}

The field part of thestudy was conducted from February to March 2004.

A field protocol was developed to ensure uniformity and smooth conduct of the surveys and also to ensure quality. A national team was formed to oversee the survey activities including the training of staff. The field investigators were the school health staff, including doctors and nurses of the respective district. A standardization training workshop was organized before the field part of the study to detail the survey methodology. All aspects of the ICT kit procedure were explained and demonstrated to the field staff. The staff were given hands-on training followed by a field evaluation of the acquired skills to ensure quality. Each survey team consisted of 1 doctor and 2 staff nurses. One nurse filled the data collection forms while the other collected blood samples and performed the ICT test. The doctor was responsible for reading the card results and overall quality control. Data were collected onto pre-tested school forms.

\section{ICT test kit}

The NOW ICT filariasis kit (catalog no. 620-000, Binax Inc.) was used for the qualitative detection of $W$. bancrofti antigen. The tests were developed and read according to the manufacturer's instructions. The test is useful for the demonstration of the $W$. bancrofti antigen at any time of the day and with any accessible population. A $100 \mu \mathrm{L}$ blood sample collected by fingerprick during the day was added without pre-treatment to a pink and white sample pad coupled to colloidal gold that contained dried polyclonal antibody (PAb) and monoclonal antifilarial antibody (MAb) respectively. The teams were asked to conduct the tests in lots of 10 students to ensure a smooth flow of the test procedures. The results were read after 10 minutes. The test was recorded positive if 2 lines (test and control) were seen in the viewing window, even when the test line appeared lighter or darker than the control line. The test was considered invalid if the control line did not appear; the test was then repeated according to the manufacturer's instructions.

\section{Ethics}

The study was approved by the Omani Ministry of Health and regional health administrators as well as the Regional Committee of the World Health Organization Regional Office for the Eastern Mediterranean. The students as well as the parents and community at large were briefed about the purpose of the survey. Informed consent was obtained before conducting the survey.

\section{Statistics}

The data were computed and analysed using the statistical program Epi-Info 2000. Frequencies, proportions and prevalence rates were calculated.

\section{Results}

A total of 2745 students aged 17-18 years were subjected to antigenaemia testing with a minimum of 250 students

\begin{tabular}{|c|c|c|c|c|c|}
\hline \multirow{2}{*}{ Region/district } & \multirow{2}{*}{$\begin{array}{c}\text { No. of } \\
\text { schools }\end{array}$} & \multicolumn{3}{|c|}{ No. of children tested } & \multirow{2}{*}{$\begin{array}{l}\text { No. antigen- } \\
\text { positive }\end{array}$} \\
\hline & & Boys & Girls & Total & \\
\hline \multicolumn{6}{|l|}{ South Bathinah } \\
\hline Rustaq & 5 & 243 & 263 & 506 & 0 \\
\hline Musannah & 4 & 173 & 174 & 347 & 0 \\
\hline Barka & 4 & 210 & 148 & 358 & 0 \\
\hline Wadi Maawil & 2 & 99 & 136 & 235 & 0 \\
\hline Nakhl & 3 & 128 & 167 & 295 & 0 \\
\hline Al Awabi & 4 & 108 & 149 & 257 & 0 \\
\hline \multicolumn{6}{|l|}{ Dhofar } \\
\hline Salalah & 7 & 233 & 266 & 499 & 0 \\
\hline Taqah & 5 & 138 & 110 & 248 & 0 \\
\hline Total & 34 & 1332 & 1413 & 2745 & 0 \\
\hline
\end{tabular}

in each of the 8 districts. A total of 1998 (72.8\%) were from South Batinah region and the remaining 747 (27.2\%) were from Dhofar region. The study subjects were from classes belonging to 34 randomly selected secondary schools in the study areas. The male to female ratio was 0.9:1.

Of the 2745 tested, none of the students tested positive for circulating W. bancrofti antigen (Table 1). During the surveys 2 card tests were doubtfully positive in South Batinah region and 14 cards were read as invalid in Dhofar region. These tests were repeated later and also found to be negative.

\section{Discussion}

LF is uncommon in Oman. The endemicity status is uncertain [6]; however some areas have been suggested as endemic areas [4]. Only 15 cases of LF were reported in Oman during the surveillance period 1991-2001. Most cases were classified as imported [6].

In our LQAS surveys of $2745 \mathrm{sec}-$ ondary-school studentsin South Batinah region and Salalah and Taqah districts of the Dhofar region, all were uniformly antigen-negative and therefore none of the study districts were LF endemic. Other countries have used detection of 
antigenaemia by the ICT card test in surveys to estimate the prevalence of $\mathrm{LF}$ infection (Table 2). Similar to our study, the prevalence of LF was zero in some studies in Trinidad [16,17].

Itisgenerallybelieved thatthevectors of LF are abundant in Oman, although the specific mosquito species have not been formally identified. Nevertheless, LF is most likely not endemic in Oman. The existence of isolated infected cases in areas where transmission is extremely unlikely (e.g. immigrants from a LF endemic country to a nonendemic country) does not require development of a national LF elimination programme. Such a situation requires implementation of a passive surveillance system by testing blood routinely collected from military recruits, university students, blood donors and hospitalized patients. Similarly, examination of blood samples from expatriates and treatment of infected subjects would also be necessary.

\section{Conclusions}

The prevalence of filarial antigenaemia among students aged $17-18$ years in the

\begin{tabular}{llcl}
\hline \multicolumn{4}{l}{ Table 2 Prevalence of lymphatic filariasis by antigenaemia in selected countries } \\
\hline Study reference & \multicolumn{1}{c}{ Country } & Prevalence (\%) & Study subjects \\
Present study & Oman & 0.0 & Schoolchildren \\
{$[16]$} & Trinidad & 0.0 & Schoolchildren \\
{$[17]$} & Kuwait & 18.3 & Adults \\
{$[18]$} & Cambodia & 0.7 & Adults \\
{$[19]$} & Suriname & 0.22 & Adults \\
{$[20]$} & Nigeria & 22.5 & Adult males \\
{$[21]$} & Uganda, Alebtong & 29.0 & Schoolchildren \\
{$[21]$} & Uganda, Lwala & 18.0 & Schoolchildren \\
{$[21]$} & Uganda, Obalanga & 30.0 & Schoolchildren \\
{$[13]$} & Egypt & 17.2 & Schoolchildren \\
\hline
\end{tabular}

suspected transmissible areas was zero. From this evidence it can reasonably be concluded that LF is not endemic in Oman and there is no evidence of its transmission.

The data suggest that Oman could seek to be awarded a certificate of LF elimination.

\section{Acknowledgements}

We are grateful to the WHO Regional Office for the Eastern Mediterranean for providing the Binax ICT kits free of charge for the survey as well as providing technical expertise. We are thankful to Dr Ali Jaffer Mohammed, Advisor Health Affairs and the survey staff and the Directorate staff from South Batinah and Dhofar region for completion of the survey.

We also thank the Regional Directorate General of Education, schools principals and teachers for their exceptional cooperation and the students for the participation. We acknowledge the excellent support of the regional teams of doctors and health inspectors for this study.

\section{References}

1. Ottesen EA. Major progress toward eliminating lymphatic filariasis. New England Journal of Medicine, 2002, 347(23):18851886.

2. Zagaria $\mathrm{N}$ and Savioli L. Elimination of lymphatic filariasis: a public-health challenge Annals of Tropical Medicine and Parasitology, 2002, 96(Suppl. 2):3-13.

3. Out filariasis now. Report of the second meeting of the Global Alliance to Eliminate Lymphatic Filariasis. New Delhi, World Health Organization Regional Office for South-East Asia, 2002.

4. Ottesen EA et al. Strategies and tools for the control/elimination of lymphatic filariasis. Bulletin of the World Health Organization, 1997, 75:491-503.

5. Regional strategic plan for elimination of lymphatic filariasis (2004-2007). New Delhi, World Health Organization Regional Office for South-East Asia, 2004 (SEA-FIL-29).

6. El Setouhy M, Ramzy RM. Lymphatic filariasis in the Eastern Mediterranean Region: current status and prospects for elimination. Eastern Mediterranean Health Journal, 2003, 9(4):534-541.
7. DCD Division of Communicable Disease Control annual report 2002. Cairo, World Health Organization Regional Office for the Eastern Mediterranean, 2002:7.

8. Chapter 9: morbidity and mortality. Tables 9-15. In: Annual health report. Muscat, Oman Ministry of Health, 2001.

9. Scrimgeour EM et al. Bancroftian filariasis in residents of Oman. Acta Tropica, 2001, 79(3):241-244.

10. Weil GJ, Lammie PJ, Weiss N. The ICT filariasis test: a rapid format antigen test for diagnosis of bancroftian filariasis. Parasitology Today, 1997, 13:401-404.

11. Ramzy RM et al. Field evaluation of a rapid-format kit for diagnosis of bancroftian filariasis in Egypt. Eastern Mediterranean Health Journal, 1999, 5:880-887.

12. Njenga SM, Wamae, CN. Evaluation of ICT filariasis card test using whole capillary blood: comparison with Knott's concentration and counting chamber methods. Journal of Parasitology, 2001, 87:1140-1143.

13. Ramzy RM et al. Efficient assessment of filariasis endemicity by screening for filarial antigenaemia in a sentinel population. Transactions of the Royal Society of Tropical Medicine and Hygiene, 1994, 88(1):41-44. 
14. Chandrasena TG et al. Evaluation of the ICT whole-blood antigen card test to detect infection due to Wuchereria bancrofti in Sri Lanka. Transactions of the Royal Society of Tropical Medicine and Hygiene, 2002, 96(1):60-63.

15. Preparing and implementing a national plan to eliminate lymphatic filariasis (in countries where onchocerciasis is co-endemic). Geneva, World Health Organization, 2000:7-8 (WHO/CDS/ CPE/CEE/2000.16).

16. Rawlins SC et al. Evidence for the interruption of transmission of lymphatic filariasis among schoolchildren in Trinidad and Tobago. Transactions of the Royal Society of Tropical Medicine and Hygiene, 2004, 98(8):473-477.

17. Iqbal J, Sher A. Determination of the prevalence of lymphatic filariasis among migrant workers in Kuwait by detecting circulating filarial antigen. Journal of Medical Microbiology, 2006 , 55(4):401-405.
18. Leang R et al. Assessment of disease and infection of lymphatic filariasis in Northeastern Cambodia. Tropical Medicine and International Health, 2004, 9(10):1115-1120.

19. Rawlins SC et al. Lymphatic filariasis in the Caribbean region: the opportunity for its elimination and certification. Revista Panamericana de Salud Publica, 2000, 7(5):319-324.

20. Eigege $A$ et al. Rapid assessment for lymphatic filariasis in central Nigeria: a comparison of the immunochromatographic card test and hydrocele rates in an area of high endemicity. American Journal of Tropical Medicine and Hygiene, 2002, 68(6):643-646.

21. Onapa AW et al. Lymphatic filariasis in Uganda: baseline investigations in Lira, Soroti and Katakwi districts. Transactions of the Royal Society of Tropical Medicine and Hygiene, 95(2):161-167.

\section{Global Programme to Eliminate Lymphatic Filariasis}

In 1997, as a result of advances in the diagnosis and treatment of lymphatic filariasis, the disease was classed as one of 6 infectious diseases considered to be "eradicable" or "potentially eradicable". Consequently, the World Health Assembly adopted resolution 50.29, calling for elimination of the disease as a global public health problem. A report on the Global Programme was recently published in the Weekly Epidemiological Record:

Global programme to eliminate lymphatic filariasis - Progress report on mass drug administration in 2009. Weekly Epidemiological Record, 2010, 85(38):365-372.

The full article can be accessed in French and English at: http://www.who.int/lymphatic_filariasis/policy/en/ 